\title{
PHOTOGRAMMETRIC RECORDING OF ANCIENT BUILDINGS BY USING UNMANNED HELICOPTERS----CASES IN CHINA
}

\author{
Zhe Li*, Yan Li \\ National Key Lab of Ancient Buildings Surveying, Architecture School, Tian Jin University, No.92 Wei Jin Road, \\ Nankai Tian Jin, China-Lee_uav@tju.edu.cn \\ Supported by the National Science Foundation of China project(No.51008204) "Spatial Data Acquisition and \\ Analysis Research of Historic Settlements"
}

KEY WORDS: unmanned helicopter, survey, architectural heritage

\begin{abstract}
:
The survey of ancient buildings is complex work. Chinese wooden buildings, with their complex structure and exquisite decorations, pose a great challenge for survey work. Therefore, it is necessary to introduce unmanned-helicopter photogrammetry and laser scanning technology to facilitate the work. This paper uses three cases to explain the application of these new technologies in China's architectural heritage protection and analyzes the special features and main operational techniques of the survey work.
\end{abstract}

\section{INTRODUCTION OF THE CASES}

The survey of ancient Chinese buildings was initiated by some architects in the early 20th century, and has now developed into a required course for architecture undergraduates. Over the years, surveys have largely been done by hand. Workers climbed up buildings and measured with rulers, levellers and laser rangefinders. It was not until the early 21 st Century when laser scanning, close-range photogrammetry were used that the efficiency and automation of the work were greatly improved. Especially after the introduction of low-altitude helicopter shooting platform, the advantages of close-range photogrammetry and aerial photogrammetry were combined and the efficiency of the work were greatly improved. This paper introduces three cases, briefly analyzes the features of ancient buildings, their difference with other cultural relics, the special requirements of unmanned helicopter survey, and follow-up data processing methods.

\subsection{Case 1: The survey and damage investigation of Ying} County Wooden Pagoda

The 67.31-meter Ying County Wooden Pagoda is located in Shanxi Province. Built in AD 1056, the pagoda is the world's oldest all-wooden structure. Entrusted by the State Administration of Cultural Heritage, Tianjin University Architecture School conducted a survey and damage investigation on the pagoda with a $3 \mathrm{D}$ laser scanner and a helicopter-photogrammetric system. Laser scanner successfully completed the scanning of the interior and the lower half of the exterior, but failed to scan the top (Figure1). Since it was very dangerous for workers to climb up to the top, a Nikon D80 camera installed on a gasoline-powered unmanned helicopter was used for a panoramic shooting. The pictures taken (Figure2) were processed with a Photomodeler software using the manual mark point processing methods, resulting in a virtual 3D model (Figure3), with an accuracy of centimetres. Experts in ancient architecture thus reached a conclusion: the top is in good condition; the roof and the tiles have no obvious shifts, which means the interior wooden frame has very little deformation and only a part of the tiles are damaged.
This is the first high-precision survey of ancient buildings in China done with an unmanned helicopter. Although we only obtained pictures of the top, we can see that the method will have good application and broad prospects. Previously, limited by perspectives, ground-based shooting and survey of ancient tall buildings were not easily done. With the introduction of aerial photography, close-range photogrammetry has become one of the surveying techniques for ancient buildings. Unmanned helicopters, with their small size and great manoeuvrability, meet the requirements for close-range and multi-dimensional shooting.

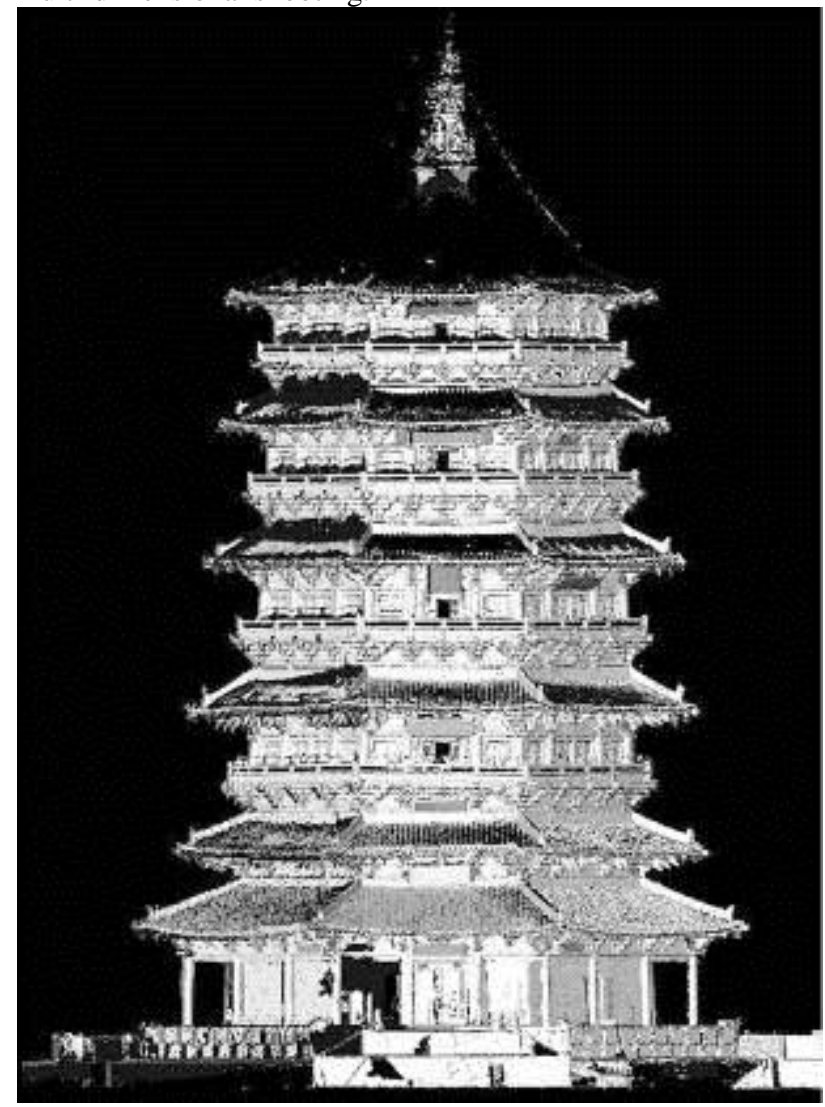

Figure1: Point Cloud of Pagoda by laser scanner 


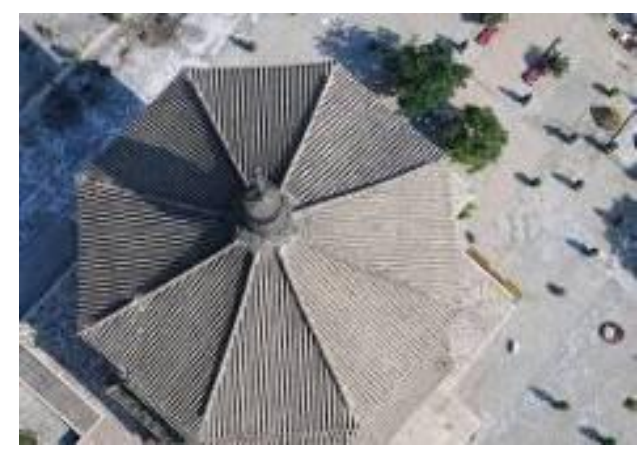

Figure2: Top of Ying Xian Pagoda (aerial image by unmanned

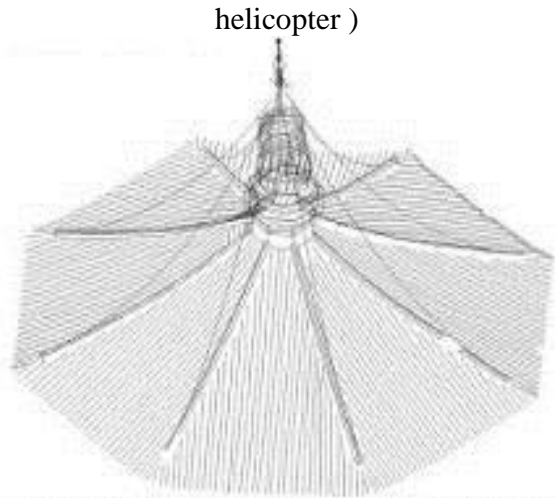

Figure 3: 3D model in CAD software

After we completed the survey of the top, we found the survey of the lower railings, eave brackets and other components ( Figure4) extremely difficult. At that time we had not grasped the technique of obtaining point clouds through photogrammetry, so it was very time-consuming to draw the railings and other components manually. Now the survey of the components of wooden Chinese buildings remains an unsolved problem.

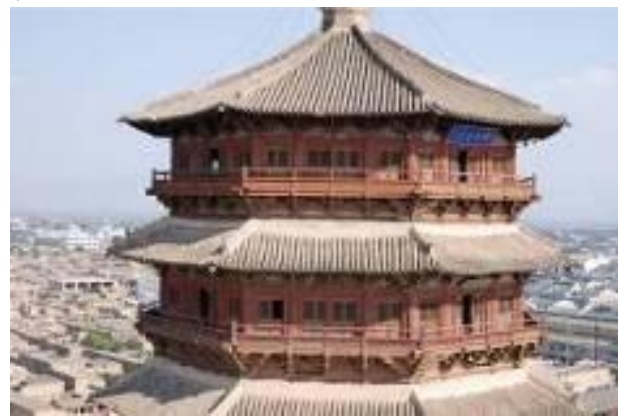

Figure4: Façade of Pagoda (aerial image by unmanned helicopter )

\subsection{Case 2: The survey of St. Louis Cathedral}

St. Louis Cathedral, built in 1872 in a former French leased territory in central Tinajin, is one of the oldest churches in Northern China. With a history of 139 years, it now stands as a DU building (Figure5). The Tianjin Municipal Government decided to renovate it in 2008. Though not very tall, the dangerous building made manual survey impossible. Photogrammetry was therefore adopted, using a 22 million pixel camera. Aerial photographs (Figure6) and ground-taken photographs were processed with a Photomodeler software to extract spatial data of feature points, on the basis of which the elevation and floor plan were made manually (Figure7).

The interior of the cathedral is tall and spacious, good for photogrammetric operations. Different from the exterior shooting, the flying platform was not used for the interior. For a better exposure, artificial light was used as supplement. The survey of the exterior and interior employed the same coordinate system. Therefore, although shootings were done separately, the hand-drawn maps of the exterior and interior could be integrated by CAD software to form a complete building profile (Figure8).
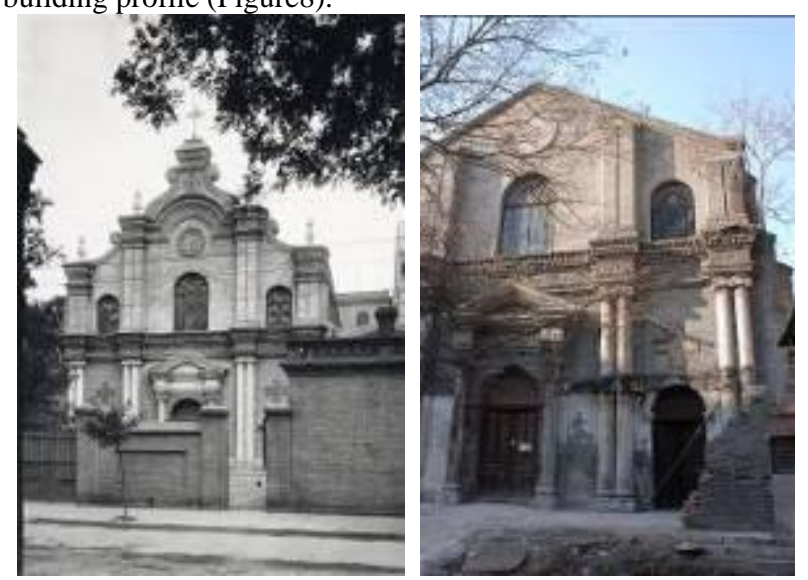

Figure5: St.Louis Cathedral (left: taken in 1950s, right: taken in

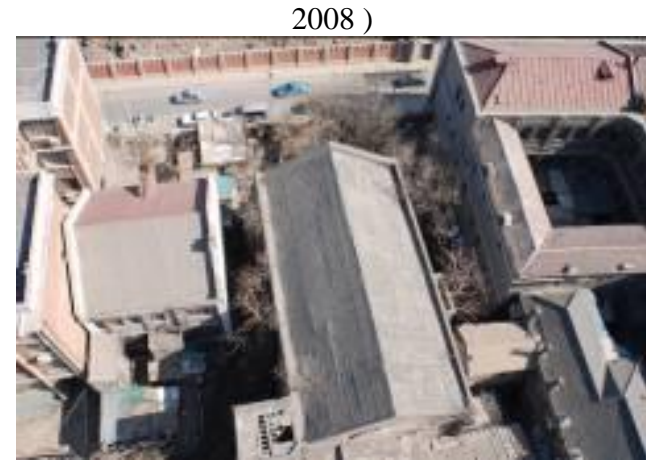

Figure6: birdview of St.Louis Cathedral

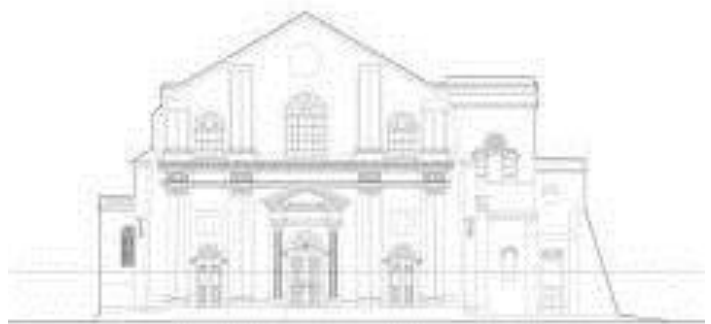

Figure7: elevation of St.Louis Cathedral

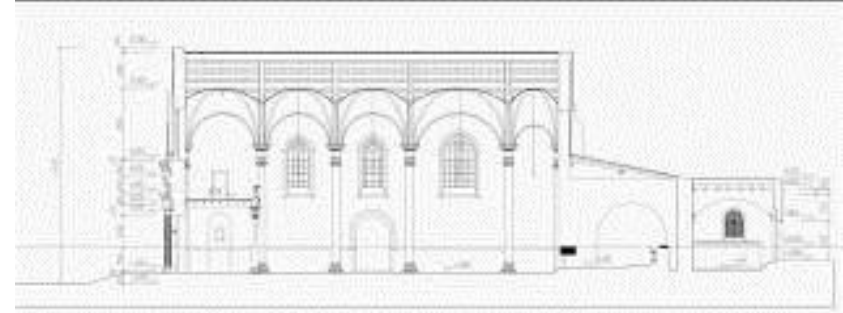

Figure8: section of St.Louis Cathedral

Without the aerial photographs, the precision of orientation would have decreased and the roof remained a blind area. The building has serious differential settlements, so the best survey method is to obtain the relative elevation of different roof points. In this case, the unmanned helicopter undertook limited amount of work but its work was very important. 
1.3 Case 3: The survey of Muslim buildings and decorations (uncompleted, currently under way)

There are a large number of Muslim buildings in northwest China. Like the St. Louis Cathedral, these buildings incorporate some structural characteristics of Chinese buildings while preserving ethnic and religious characteristics of their own. For example, Muslims love to decorate the façade with patterns of flowers and plants. This tradition is carried forward to become the most redundant and complex façade decoration in the world (Figure9)

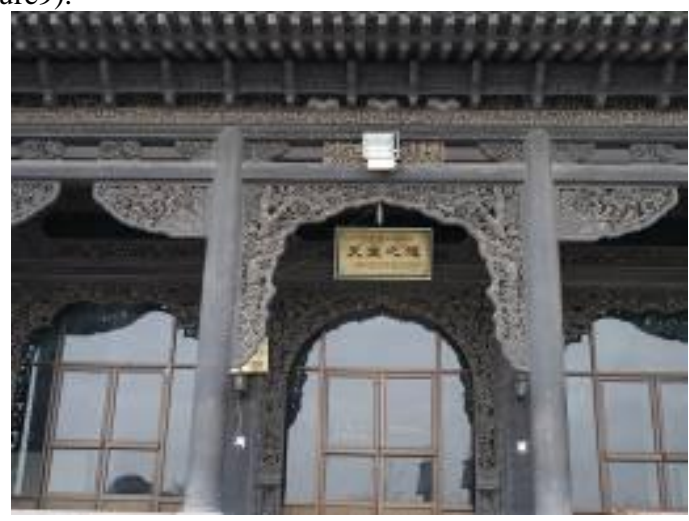

Figure9: decorated brace of Banqiao Mosque

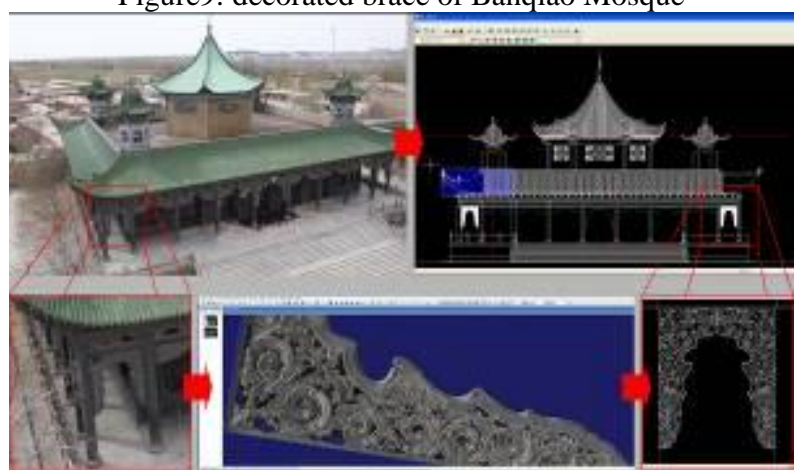

Figure10: mapping process of decorated brace of Banqiao

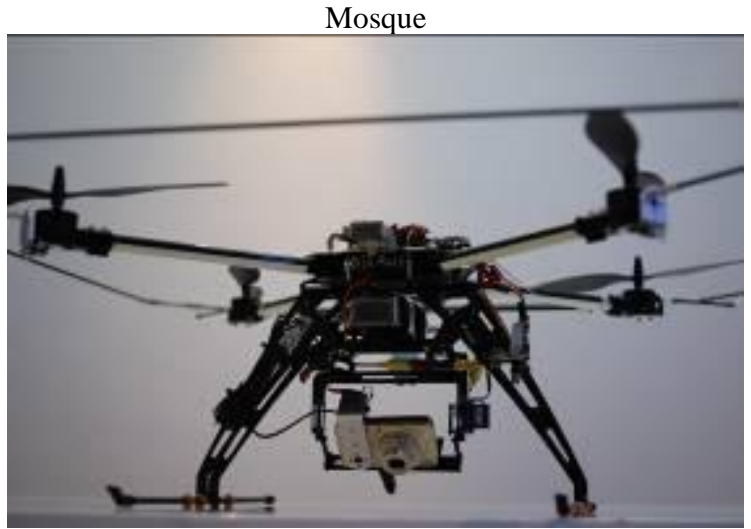

Figure11: micro Quadcopter for taking close range images With an unmanned helicopter, we had little difficulty in obtaining the elevation of the building, but the survey of complex decoration poses a challenge. Previously, an approximate orthophoto was taken and entered into a CAD software for manual drawing. The method had its disadvantages: it was very time consuming; the more complex the decorative patterns, the more difficult the survey was. Therefore, the author attempted to use a mini four-rotor machine (Figure11) to do super close-up shooting, obtained point clouds of complex decoration components through photogrammetry, set up a surface model DSM, automatically obtained a CAD DLG of components through capturing the contours, and then integrated the DLG with the elevation of the building (Figure10).

As the relief decorative patterns are complex and varied in details, the first DLG obtained was not very satisfactory. Further experiments need to be done to improve the point cloud quality of relief members along the depth.

\section{EVALUATION OF HELICOPTER- PHOTOGRAMMETRY}

Based on the above experiment on Photogrammetry and other relevant practices in China, we come to the following conclusions:

2.1 Unmanned helicopter-based photogrammetry is an essential and irreplaceable means in the survey of ancient buildings.

After the introduction of low-altitude photogrammetric system, surveyors do not need to climb up ancient buildings. This improves the survey efficiency, and more importantly, protect both the surveyors and the buildings. Apart from the danger, manual survey may inevitably damage roof tiles, which will have to be mended after the completion of the survey.

Laser scanning is easier to learn than Photogrammetry, but it cannot obtain complete survey data due to its ground-based limitations. When close-range photogrammetry is combined with a mobile shooting platform, namely, an unmanned helicopter, to form an "aerial close-range photogrammetry system ", surveys will be more efficient and the data obtained will be more complete.

\subsection{A combination of different techniques to better accomplish the survey of ancient buildings}

Ground-based laser scanner is fit for the survey of the interior and sections close to the ground, while close-range photogrammetry system is fit for the survey of facades and top as well as for the rapid survey of a building complex.

Low-altitude photogrammetry will not completely replace manual survey, ground photogrammetry and laser scanning. Various means should be combined to make "aerial-ground survey of ancient buildings".

2.3 The Lidar system represents one direction of the technical development.

When a Lidar system of unmanned helicopter reaches a scanning precision of centimeter or even higher, it can be applied to the survey of the ancient buildings. In addition to photogrammetry, UAV has broader applications.

2.4 Different from topographic mapping, machines cannot fully replace manual drawing in the survey of ancient buildings.

The output of survey results requires architectural expertise. Point clouds can not entirely replace drawings. Structural knowledge is needed to convert building components into drawings. Data are to be processed and drawings are to be done manually. 
2.5 Chinese architects should welcome the new type of survey results brought about by new techniques.

Point clouds and 3D model are fit for the recording of curved surface. Previously, two-dimensional drawings are the only type of drawing in the survey of ancient buildings. Nowadays digital results like 3D and visualization should be accepted.

\section{KEY POINTS FOR THE APPLICATION OF LOW- ALTITUDE HELICOPTER-PHOTOGRAMMETRY}

\subsection{Sectional treatment of complex objects is the key to the survey of ancient buildings.}

Ancient Chinese buildings can be taken as a combination of several survey objects and different survey methods are to be used respectively.

\begin{tabular}{|c|c|c|}
\hline $\begin{array}{l}\text { Name of the } \\
\text { parts }\end{array}$ & $\begin{array}{l}\text { External } \\
\text { features }\end{array}$ & $\begin{array}{l}\text { Photogrammetric instruments and } \\
\text { survey methods to be used }\end{array}$ \\
\hline $\begin{array}{l}\text { 1. The main } \\
\text { body of the } \\
\text { building (eg. } \\
\text { the basic curve } \\
\text { of the roof and } \\
\text { foundation, } \\
\text { etc.) }\end{array}$ & $\begin{array}{l}\text { Simple and } \\
\text { having } \\
\text { beautiful lines }\end{array}$ & $\begin{array}{l}\text { Either to generate dense point } \\
\text { clouds to facilitate drawing or } \\
\text { manually obtain 3D data of feature } \\
\text { points for orthographic projection } \\
\text { drawings. Note that this will be the } \\
\text { skeleton (basis) of a CAD graph, } \\
\text { other parts will be added in. A } \\
\text { larger helicopter and close-range } \\
\text { multi-dimensional shooting are } \\
\text { preferred. }\end{array}$ \\
\hline $\begin{array}{l}\text { 2. 3D curved } \\
\text { surface (eg. } \\
\text { Wenshou) }\end{array}$ & $\begin{array}{l}\text { Small in } \\
\text { number, } \\
\text { varied } \\
\text { shape, } \\
\text { standing } \\
\text { alone, having } \\
\text { a curved and } \\
\text { glazed surface }\end{array}$ & $\begin{array}{l}\text { For fine mapping, point clouds } \\
\text { should be generated and converted } \\
\text { into surface models and chartlet. A } \\
\text { contour map can be further } \\
\text { generated and processed with CAD. } \\
\text { Mini helicopter is used to conduct } \\
\text { close-range shooting on both sides. } \\
\text { The respectively generated point } \\
\text { clouds are then made into one } \\
\text { model. }\end{array}$ \\
\hline $\begin{array}{l}3 . \quad \text { Wooden } \\
\text { component } \\
\text { group of } \\
\text { regular } \\
\text { geometric } \\
\text { shapes (such } \\
\text { as eave } \\
\text { brackets) }\end{array}$ & $\begin{array}{l}\text { Intricate } \\
\text { relations } \\
\text { among } \\
\text { components; } \\
\text { the most } \\
\text { complicated } \\
\text { part in the } \\
\text { survey of } \\
\text { ancient } \\
\text { Chinese } \\
\text { buildings }\end{array}$ & $\begin{array}{l}\text { Close-range shooting to generate } \\
\text { point clouds might be a faster way. } \\
\text { Structural knowledge of ancient } \\
\text { buildings is needed. Shooting } \\
\text { platform depends on the height and } \\
\text { size of the components. }\end{array}$ \\
\hline $\begin{array}{l}4 . \quad \text { Relief } \\
\text { ornaments (eg. } \\
\text { Queti and } \\
\text { screen walls ) }\end{array}$ & $\begin{array}{l}\text { Varied } \\
\text { patterns and } \\
\text { rich lines, } \\
\text { characterized } \\
\text { by the uneven } \\
\text { surface }\end{array}$ & $\begin{array}{l}\text { For fine mapping, we can only } \\
\text { generate point clouds and surface } \\
\text { model, and then capture contours to } \\
\text { generate a CAD graph. To obtain a } \\
\text { better contour, a baseline alone is } \\
\text { not enough. Shooting should be } \\
\text { done from different angles to get } \\
\text { point clouds along the depth. (We } \\
\text { are now experimenting on the } \\
\text { method.) }\end{array}$ \\
\hline $\begin{array}{ll}5 . & \text { Interior } \\
\text { space } & \end{array}$ & $\begin{array}{l}\text { Complex in } \\
\text { shape; dim; } \\
\text { inadequately } \\
\text { and unevenly } \\
\text { illuminated }\end{array}$ & $\begin{array}{l}\text { We mainly rely on 3D laser scanner } \\
\text { to obtain point clouds to do the } \\
\text { drawing. If photogrammetry is } \\
\text { used, high-power, multi- } \\
\text { dimensional fill light is needed to } \\
\text { get similar effect of outdoor. }\end{array}$ \\
\hline
\end{tabular}

Table 1. Different parts and survey methods

Compared with the average above-ground cultural relics, ancient buildings are more complicated with their fixed structures and complex interior, but they can also be seen as composed of different parts, which can be surveyed with various tools. Survey can be done section by section in a unified coordinate system with overall error control. The final result is a combination of each part.

In the survey, shooting distance varies with the size of target. Therefore, helicopter platforms of various sizes are used to ensure safety. Building components close to ground can be shot manually.

3.2 Good image quality, including sharpness, contrast and brightness, is the basis of successful mapping of ancient buildings.

To generate high-quality point clouds, we need the best image quality. The tile roof and brick walls of ancient Chinese buildings can be seen as targets of repetitive texture, and only a high-resolution camera can capture the detailed characteristic texture of each tile component and obtain the correct 3D point clouds. So we need to improve the image quality from the following aspects:

3.2.1 High-pixel digital camera is preferred.: Single stereogram should reach a resolution of millimeters. The relations between camera pixels and shot objects are as follows:

\begin{tabular}{|c|c|c|}
\hline $\begin{array}{l}\text { Size of CCD ( } \\
\text { megapixel) }\end{array}$ & $\begin{array}{l}\text { Maximum Size of } \\
\text { target (meter) }\end{array}$ & $\begin{array}{l}\text { Maximum Size of } \\
\text { Point-Cloud (meter) }\end{array}$ \\
\hline 12 & $3.2 * 2.4$ & $2.4 * 2.4$ \\
\hline 22 & $5.5 * 3.7$ & $3.7 * 3.7$ \\
\hline 40 & $7.2 * 5.4$ & $5.4 * 5.4$ \\
\hline 60 & $8.9 * 6.6$ & $6.6 * 6.6$ \\
\hline
\end{tabular}

Table 2. Size of CCD and Point Cloud

3.2.2 Aperture should be small: Aperture should be as small as possible to ensure the depth of field is large enough so that the image of each part of the building is clear. Cameras of 40 million-pixel is sensitive to lens depth of field, so when aperture value stands at 5 or 6 , the clarity of far and near objects declines.

3.2.3 Clean air with full clouds in the sky is the best weather for the survey. In strong sunlight, exposed and shaded areas of the building form sharp contrast, which creates difficulty for the search of feature points.

3.2.4 The moving and vibration of the helicopter should be as little as possible. Generally, gasoline-powered helicopter is equipped with a multi-level vibration-reduction installation between the fuselage and the camera, but there are still some vibration transmitted to the camera. The larger the pixels are, the more sensitive the camera is to vibration. A 10 million-pixel camera with an internal combustion engine is still workable, while a 40 million one fails to work properly. For demanding survey project, flying vehicles with low vibration is preferred, such as turbine or electricpowered helicopter. Through our test, we find that the vibration intensity of turbine helicopters is only $1 / 5$ or even lower than gasoline-powered helicopters, thus the image obtained will be clearer.

Helicopters used in the survey of ancient buildings can be automatically or semi-automatically navigated, that is, they only need to have automatic hovering functions. In addition, the requirements on flight attitude stability are demanding. Flight control system should not only rely on GPS signals to do self-positioning, but also should have optical lock-on or 
other redundant, high-precision positioning mode, which is very important for ultra-low-altitude narrow-space flight.

\section{WHY DO WE USE HELICOPTER INSTEAD OF OTHER LOW-ALTITUDE PLATFORM LIKE THE BALLOONS?}

Thread-pulled balloons or airboats can also be used in lowaltitude shooting, but due to the following disadvantages, they are not used in the above cases.

4.1 It is uneconomical to use and inconvenient to carry helium.

4.2 Helicopters are more flexible and can quickly adjust their angles and position. Their movements are quick and easy.

4.3 The vibration of helicopters is greater than balloons, but as the technology of turbojet and electric helicopter matures, vibration disturbance is decreasing and the advantages of balloons are no longer obvious.

Of course, with adequate gas supply and easy transportation, thread-pulled balloons, long arm and other shooting platforms can also be used. In the survey of the interior of St.Louis Cathedral, we used a long arm to shoot objects in higher positions. To obtain photos of certain angles with minimum costs and fastest speed is the major purpose of photogrammetric field work.

\section{References from websites:}

Eisenbeiss, H., Zhang, L., COMPARISON OF DSMS GENERATED FROM MINI UAV IMAGERY AND TERRESTRIAL LASER SCANNER IN A CULTURAL HERITAGE APPLICATION, ISPRS Commission V Symposium, Image Engineering and Vision Metrology, Dresden, Germany, 25.-27. September, 2006

Lambers, K., Eisenbeiss, H., Sauerbier, M., Combining photogrammetry and laser scanning for the recording and modelling of the late intermediate period site of Pinchango Alto, Palpa, Peru, J. Archaeol. Sci. , doi:10.1016/j.jas.2006.12.008,2007

Eisenbeiss, H., Gruen, A., Model helicopter over Pinchango Alto, Peru ,The Japanese Journal of Survey, Vol. 56 No. 5, pp. 34-37,2006

Eisenbeiss, H., APPLICATIONS OF PHOTOGRAMMETRIC PROCESSING USING AN AUTONOMOUS MODEL HELICOPTER, ISPRS Commission I Symposium, Paris, France, 03.-06. July, 2006 (http://www.photogrammetry.ethz.ch/research/publications.html) 